\title{
RELIGIONES E IDENTIDADES: \\ OPORTUNIDADES PARA \\ UNA SOCIEDAD TOLERANTE Y DEMOCRÁTICA
}

José Luis González*

\section{Introducción}

Recuerdo que, con ocasión de una de las actividades generadas en torno a la efervescencia 1992, participando en un animado debate sobre el tema de las identidades colectivas americanas, tuve oportunidad de escuchar a un prominente filósofo mexicano que sostenía la falta radical de sentido de expresiones tales como 'identidad cultural' o 'identidad étnica'. Desde los principios de la ontología, según él, ningún ser humano puede compartir su identidad con otro congénere. Cada ser humano es idéntico consigo mismo y sólo consigo mismo. Podrá compartir el género y la especie, la naturaleza, pero no su 'identidad'. En realidad, éstos son los planteamientos filosóficos desde Aristóteles.

La anécdota ponía de manifiesto dos hechos fundamentales: a) la persistencia de la 'filosofía perenne' todavía vigente en la Academiá y b) la insuficiencia de la filosofia para dar cuenta del fenómeno humano en su totalidad. Una de las audacias más saludables que las ciencias sociales 'cometieron' ante la filosofía es el haberle disputado su derecho supuestamente exclusivo a tratar de lo humano. Es desde esta osadía como ha venido siendo recurrente en los ámbitos de la antro-

* ENAH; ITAM. 
JOSÉ LUIS GONZÁLEZ

pología, lingüística, psicología social, semiótica y la sociología el tema de las identidades colectivas como concepto epistemológicamente interdisciplinario y transterritorial.

El núcleo de nuestra reflexión, digámoslo desde el comienzo, es la identidad cultural o identidades culturales que pueden reconocerse tanto en la sociedad como en el territorio mexicanos. Una identidad colectiva que parece puesta a prueba por una serie de hechós recientes que dan la impresión de poder 'desquiciarla', 'descentrarla' o, según los más pesimistas, acabar con ella. Los cambios que, desde hace unas décadas, afectan a la composición religiosa de la sociedad mexicana, constituyen, a juicio de muchos, uno de los desafios más medulares que parece enfrentar la identidad nacional mexicana.

\section{En la encrucijada del concepto}

Desde el nivel más elemental, la identidad, en su expresión colectiva, no es sino la abstracción epistemológica de un nosotros social y/o cultural. Allá donde reconocemos un 'nosotros' que nos envuelve, reconocemos también una identidad que nos incluye. Si lloramos a un mismo muerto, si veneramos a un mismo dios o si celebramos una misma fiesta patria estamos reconociéndonos como parte de diversas identidades colectivas: la familia, la etnia y el estado-nación. Por tanto, la acepción elemental y mínima que puede tener la 'identidad colectiva' es en referencia a un cierto número de individuos que se sienten, de alguna forma, ligados unos a otros y que tienen conciencia de formar una colectividad. Dentro de esa abstracta elementaridad caben, por supuesto, realidades y fenómenos muy diversos tanto por la naturaleza de las causas que los originan (económicas, culturales, políticas, raciales, religiosas, etc.) como por los fines inmediatos que persiguen y por la forma en que se expresan en relación con otras identidades.

La identidad colectiva es, en mi opinión, una noción cuyo único objeto y fin es el dotarnos para el momento de un máximo 


\section{RELIGIONES E IDENTIDADES}

común divisor aplicable a los fenómenos y situaciones bastante heterogéneas pero que tienen en común esta existencia, $o$, mejor dicho, este combate por la identidad. ${ }^{1}$

Pero más que una definición, lo que ayuda a entender y precisar el concepto de identidad es el análisis de los niveles de significación o dimensiones que están implícitos en el mismo.

El mismo Jacques Berque enumera cinco pares de conceptos como elementos integrantes de la dialéctica propia de una 'identidad colectiva':

1. Cambio y persistencia: Con frecuencia al pensar en identidad colectiva se piensa en lo más inmutable de un sujeto social, aquello que no cambia aunque pasen los años. Sin embargo la identidad no existe sin transformación y sin cambio, pero, a la vez el cambio no es posible si no es transformación 'en nosotros', en ese nosotros que situábamos en la base de toda identidad colectiva y como su sujeto social. Desde este punto de vista la dimensión diacrónica de la identidad no es otra cosa que el sujeto social reconociéndose a sí mismo en las diferentes (¡y a veces contrastantes!) fases de su proceso histórico. Esta dialéctica entre cambio y persistencia, devenir o ser en la terminología de los viejos filósofos, adquiere una significación peculiar en la modernidad por la pretensión de universalidad con que nace la cultura moderna. El término 'modernizar' ha acompañado generalmente a políticas de 'asimilación' de otras identidades culturales dentro de la identidad emergente del Estado-Nación. De ahí la diferente intensidad de identidad que está en juego cuando hablamos de 'identidad nacional' o de 'identidad étnica'. Los franceses del XIX se reconocen parte de la misma Francia que los súbditos de Luis XrV y, sin embargo, les separa una revolución. ¿Se puede hablar, no obstante los cambios,

${ }^{1}$ J., Berque, "Identités collectives et sujets de 1'histoire", en G. Michaud (comp.), Identités collectives et relations inter-culturelles, 1978, Bruxelas, Complexe, p. 11. 
JOSÉ LUIS GONZÁLEZ

de una identidad mexicana que atraviese Teotihuacán, Tenochtitlan, Nueva España y México Independiente?

2. La identidad colectiva es a la vez y permanentemente sujeto y objeto: las identidades colectivas distintas de la nuestra son observadas por nosotros como 'objeto' (de estudio, por ejemplo); sin embargo dicha identidad como cualquier otra es subjetiva en sí misma y, a la vez, transportada y transmitida en realidades objetivas.

3. La identidad colectiva es por naturaleza activa: esto implica que todos sus elementos actúan unos sobre otros de modo que son agentes y pacientes de la actividad intercambiada. No hay factores determinantes 'en última instancia'; todos actúan sobre todos, modifican y son modificados.

4. La identidad colectiva actúa como una 'totalidad'. Se entiende a sí misma como totalidad. Totalidad susceptible de ser desmontada en sus diversos elementos. Esto quiere decir:

a. por un lado es global y globalizante:

b. pero, por otro lado, puede ser sometida a un juego interminable de análisis y diferenciaciones.

5. La identidad colectiva es 'intercambiable' en sus componentes profundos: sus formas se transforman en contenidos y sus contenidos en formas.

Evidentemente no en todos los casos de identidades colectivas que pueden ser estudiadas se darán los cinco caracteres con igual propiedad. Eso permite una clasificación de la diversidad de manifestación de las identidades colectivas.

Evidentemente, el concepto 'identidad colectiva' no es sinónimo de 'identidad étnica', pero ésta tiene algo de paradigmático por su elementariedad para la comprensión de las otras identidades colectivas. Ésa es la razón por la que el modo como se manifiesta la identidad colectiva en el grupo étnico y los elementos quie entran en juego son ilustrativos para la comprensión general de las identidades colectivas. 
RELIGIONES E IDENTIDADES

Un grupo étnico, entendido como concepto socio-histórico, dice relación con:

a. un grupo social cuya constitución se pierde en la larga duración que evoca, generalmente, estabilidad (tradición y conservación);

b. en transformación permanente y nunca acabada; y

c. en relaciones dialécticas con sus vecinos (con otros colectivos de características similares). El reconocimiento de la propia identidad implica necesariamente una referencia a 'los otros'.

Pero, más allá de este carácter 'relativo' (relacional y subjetivo) implícito en toda identidad colectiva, ésta tiene un soporte objetivo que descansa sobre estas cinco realidades que destaca Guy Michaud para las identidades étnicas: ${ }^{2}$

a. lengua común (aunque comunidad lingüística y étnica no sean lo mismo);

b. relación colectiva con un territorio generalmente estimado como propio y ligado a la historia del grupo (pero también puede ser un territorio del que se salió, en el que se sufre, en el que se lucha por derechos colectivos, etc.);

c. una cultura compartida organizada en un sistema original y propio;

d. conciencia de pertenencia que se pone de manifiesto, sobre todo, en las relaciones interétnicas o hacia el exterior;

e. voluntad de vivir cohesionados y unidos.

Podría decirse, teniendo en cuenta la confluencia de las consideraciones que anteceden y los diversos énfasis que los autores señalan,

${ }^{2}$ G. Michaud, "Mises au point", en G. Michaud, op. cit., p. 115. 
JOSÉ LUIS GONZÁLEZ

que toda identidad colectiva expresa un modo original de relación entre Naturaleza y Cultura. En el enlistado que precede, la Naturaleza, obviamente está presente en la categoría territorio pero las otras cuatro categorías, aunque pertenecen ya al plano de la Cultura, llevan en sí como elemento constitutivo fundamental la relación con esa porción de naturaleza. El territorio (aunque a veces sólo sea el terreno), independientemente de su extensión y del tipo de relación que con él se mantiene, es la porción de naturaleza sobre la que vive la colectividad y en relación con la cual se teje su identidad. Esta base natural de la sociedad es también base de su identidad, su sustrato físico.

Esta referencia al territorio o al sustrato natural de la identidad nos permite comprender el desigual comportamiento de la identidad colectiva cuando sale el individuo, la familia o segmentos del grupo de su territorio original y se establecen en otro lugar. El comportamiento ante los desafios del exterior y la misma interacción de los mecanismos internos son distintos cuando las cosas ocurren lejos de la tierra de origen. También la valoración es distinta. No se comporta de igual modo la identidad colectiva ante un factor de cambio que llega al territorio que ante el mismo factor de cambio que actúa sobre 46 miembros de la comunidad que salen de su territorio. Por otro lado son muchos los ejemplos de grupos de repatriados, desterrados o migrantes voluntarios que conservan su 'tierra ausente' como sustento de su identidad a veces agresivamente conservada ante la sociedad que los acoge. Es en esos casos que se buscan sucedáneos cercanos del territorio ausente: Club Asturiano, Centro Gallego, Hospital Español, Centro Libanés, etc. ${ }^{3}$

${ }^{3}$ La gran complejidad de la vida urbana moderna ha provocado el surgimiento de identidades colectivas en las que la referencia a un territorio propio se ha debilitado y, a veces, da la impresión de haber desaparecido. Por ejemplo los Colegios Profesionales, Asociaciones Civiles, Sociedades Anónimas, iglesias minoritarias, etc. Sin embargo la necesidad perentoria que toda asociación tiene de llegar a poseer una 'sede', un 'local', un templo o un 'domicilio' fiscal parecen indicar la persistencia de esa relación indispensable entre identidad colectiva y territorio. 
Ahora bien, por muchos factores que inciden en el concepto, la categoría territorio se está transformando. Al menos así parece indicar la tendencia de la cultura globalizante. Ser ciudadano del mundo es tener al mundo entero como territorio de referencia... En principio, dicho territorio sería el sustento nuevo de una nueva identidad colectiva globalizante. Pero esto que para algunos parecía un proceso imparable e irreversible, ha sido puesto en jaque por los procesos de reconfiguración territorial y resurgimiento étnico en Europa del Este. No sólo el mundo pareciera demasiado grande y abstracto para la identidad colectiva de la etnia, sino el mismo esquema de Estado-Nación parece poco funcional para esas fuerzas emergentes. De ahí que algunos piensen que el camino de la globalización, si no quiere ser efímero, tendrá que convertirse en un concierto 'global' de las diferencias.

En estos momentos estamos en un período de transición y dicha transición no cesará, en mi opinión, más que cuando haya una sociedad planetaria que se construya sobre nuevos tipos de diferenciación y permita que existan en su interior. Porque no habrá sujeto histórico posible sin que los componentes de ese sujeto se articulen entre ellos mismos según sus propias diferencias que no serán, ciertamente, las de la actual sociología sino otras que tendremos que poner a prueba. ${ }^{4}$

Sin duda, es este desafío uno de los rasgos de nuestra época. Por revuelta o por reivindicación, por todas partes parecen despertar sentimientos de particularismo y de diferenciación. En 1970, Henri

${ }^{4}$ J. Berque, op. cit., p. 18. Según nuestra propia traducción. "Pour l'instant nous sommes dans une période de transition et cette transition ne cessera à mon sens que lorsqu'il y aura une société planétaire, celle-ci d'ailleurs donnant naissance et reposant sur de nouveaux types de différentiation. Car il n'y aura pas de sujet historique possible sans composantes de ce sujet s'articulant elles-mêmes selon leurs propres différences qui ne seront plus celles de la sociologie présente, mais sans doute d'autres que nous aurons à mettre à l'épreuve." 
JOSÉ LUIS GONZÁLEZ

Lefebvre recogía magistralmente este rasgo 'convulsivo' de nuestro tiempo:

De manera convulsiva, a través de sufrimientos, el ser mundial de lo que todavía llamamos 'el hombre' y 'lo humano' entra en el mundo de las diferencias. Y no entra como a un país ya hecho, en un paisaje ya conocido, en una obra ya completa. Descubrimiento y creación, van juntos en todo lo que concierne a lo diferencial. ${ }^{5}$

Es esa relación entre descubrimiento y creación que Lefebvre sitúa en el núcleo mismo del proceso diferenciador, que nos permite situar el carácter dinámico de la identidad colectiva. Muchos de los problemas planteados por supuestos o reales atentados contra las identidades étnicas tienen en su raíz un falso planteamiento de esta doble dimensión dialéctica. Si toda identidad, como lo atestigua la experiencia de los procesos culturales, es constante descubrimiento y creación, los cambios y las mutaciones son parte inseparable de su naturaleza. En muchos casos habría que preguntarse si los conflictos en torno a la identidad cultural se están analizando desde los mecanismos de la identidad cultural o desde el juego de las relaciones sociales que superponen o atraviesan los procesos de identidad.

\section{Los cambios en el campo religioso: desafios a la identidad nacional?}

Tan sólo a modo de referencia global y sin entrar a detalles, permítaseme esbozar algunos contornos del proceso de cambio que la sociedad mexicana experimenta en el campo religioso. Para empezar tendríamos que reconocer que el 'campo religioso' (en el sentido que le atribuye P. Bourdieu) se ha convertido, en cierto modo, en 'campo de batalla' en el que no 'uno' sino 'muchos' cuerpos de especialistas han concen-

${ }^{5}$ H. Lefebvre, Le manifeste differentialiste, 1970, París, Gallimard, p. 93-4. 
RELIGIONES E IDENTIDADES

trado el poder de producción y gestión de bienes simbólicos y se autoatribuyen la exclusiva de la ortodoxia. ${ }^{6}$

Todo indica que, a raíz de la crisis de los paradigmas y de los grandes relatos sustentados por grandes instituciones, la evolución del campo religioso tiende al minifundio en el que impera el 'sentido local'.

Aunque el pluralismo religioso llega a México como resultado natural y lógico de la modernidad y el liberalismo, es sobre todo en las últimas décadas que tiene lugar lo que algunos han llamado la 'explosión de las sectas' refiriéndose a la creciente presencia de múltiples iglesias, confesiones y grupos religiosos cristianos, para cristianos y no cristianos. Esta presencia heterogénea va acompañada por lo general de un activo proselitismo que confronta ofertas y demandas. Los casos específicos de este proceso son muchos. Los datos de algunos estudios recientes nos ofrecen datos elocuentes. Dos ejemplos:

a. En Xalapa entre los censos de 1970 y 1980 la población total aumentó en un $40 \%$. En ese mismo período la población católica creció en un $30 \%$ mientras la protestante lo hizo en un $174 \%{ }^{7}$

b. En el sudeste mexicano el proceso ha sido más acelerado. En los estados de Tabasco y Chiapas la población no católica alcanza ya el $20 \%$ según los censos de $1980 .{ }^{8}$ En términos globales, en 50 años, la población mexicana no católica pasó de un $2.3 \%$ (1930) a un $7.4 \%(1980){ }^{9}$

${ }^{6}$ Pierre, Bourdieu, "Gènese et structure du champ religieux", en Revue Française de Sociologie, 1971, XII, p. 300-3.

${ }^{7}$ F. Vázquez, Protestantismo en Xalapa, Edo. de Veracruz, 1991, Xalapa, p. 41.También puede consultarse al respecto C. Garma Navarro, Protestantismo en una comunidad totonaca de Puebla, 1987, México, INI, p. $83 \mathrm{~s}$.

${ }^{8} \mathrm{C}$. Cardiel, y M. Villalobos, Religión y Sociedad en el sudeste de México, 1989, México, La Casa Chata, vol. vI, p. 64 s.

9 J.P. Bastian, Historia del Protestantismo en América Latina, 1990, México, CUPSA, p. 261 s. 
Estos datos tomados como indicador de una seria reconfiguración de la sociedad mexicana en materia de religión, ha obligado a poner sobre la mesa de discusión el tema de la identidad o identidades nacionales. Es claro que los cambios aludidos han afectado los niveles tradicionales de integración y cohesión culturales en muchos casos, sobre todo en comunidades indígenas o campesinas de alto grado de homogeneidad. Son abundantes los casos estudiados de comunidades que habían venido funcionando como unidades sociales y ceremoniales y que, bajo el impacto de la penetración de nuevas denominaciones religiosas, quedan divididas y con serios conflictos internos. Es frecuente el caso de comunidades en las que a partir de la irrupción de un nuevo grupo religioso quedan partidas en dos: dos credos, dos grupos ceremoniales, dos éticas, dos cosmovisiones, etc. Estos datos empíricos que pertenecen ya a lo cotidiano y que han sido tema de muchas etnografias, se han convertido en tema de fuerte debate a la hora de su valoración en relación con las identidades étnicas o la llamada identidad nacional. Si la identidad colectiva es entendida como algo absoluto e inmutable, el cambio que se está produciendo en México sería negativo y estaría atentando contra algún nivel profundo del ser mexicano. Desde esta posición sólo cabe la intolerancia radical premoderna: ¡Guerra a los enemigos! Antropólogos, políticos, líderes indígenas, sacerdotes católicos y maestros rurales estarían unidos -al menos tácticamenteen contra de las sectas y de los nuevos movimientos religiosos por ser enemigos de la identidad mexicana. En este enfoque del problema nos parece detectar una motivación y un análisis más políticos que antropológicos y, como consecuencia, una dislocación del problema.

Cabe, sin embargo, otra forma de abordar el tema y sus consecuencias. Si por identidad entendemos esa relativa pero real continuidad diacrónica y sincrónica de significados, valores, motivaciones y actitudes compartidos (etnotipo) por un grupo social (sujeto histórico portador $\mathrm{y}$ creador de dicho etnotipo) según la terminología de Guy Michaud, ${ }^{10}$

${ }^{10} \mathrm{G}$. Michaud, "L'ethnotype comme système de significations", en G. Michaud, op. cit., p. 30. 
entonces la evolución de la identidad cultural hay que situarla en la lógica de la evolución y cambio de la cultura. Por violencia o por comercio, por curiosidad o por azar, las culturas se han ofrecido unas a otras como diferentes opciones disponibles dentro de la gran producción de bienes simbólicos que tiene lugar en la aventura humana. De todas esas formas posibles de producirse el cambio y el intercambio de bienes, hoy preferimos las más civilizadas de la oferta y la demanda ejercidas con libertad dentro de un ordenamiento jurídico. La expansión compulsiva de las sectas (provocada en parte por la crisis de los grandes relatos que provoca la crítica postmoderna) se sitúa, a nuestro juicio, dentro de esta dinámica. Obviamente, como la ofensiva de 'nuevas ofertas de bienes religiosos' proviene en la mayoría de los casos del campo de la cultura occidental, tiene a su servicio los recursos más sofisticados al servicio de su difusión. En realidad la sociedad mexicana (de la española se podría decir lo mismo) no ha cambiado más en lo religioso que en, por ejemplo, los hábitos de consumo, las preferencias estéticas, etc. En todos estos aspectos de la cultura se puede decir que 'las cosas no son como antes' y sin embargo no se ha llegado a configurar como problema específico. Lo que ocurre es que al hablar de lo religioso estamos tratando de un 'campo social', en la terminología de P. Bourdieu, y un 'campo' se constituye en la medida en que un grupo de especialistas institucionalizados ha concentrado el poder de la producción y gestión de los bienes que están en juego. El cambio religioso no sería mayor problema si no consistiera en 'salir de una Iglesia para entrar en otra'. Cada vez que alguien cambia de religión una institución gana lo que otra pierde. Cuando la que pierde tiene una larga trayectoria histórica y una gran presencia social en una sociedad dada, entonces tiende a considerar sus pérdidas como pérdidas 'nacionales' dejando caer sobre el ganador la sombra de ladrón, usurpador o, quizás, traidor a la patria. 
JOSÉ LUIS GONZÁLEZ

\section{3. ¿Es posible un futuro distinto y un México no mayoritariamente católico?}

Yo lo veo posible y, desde las tendencias culturales, sociales e institucionales hoy predominantes, probable a mediano plazo.

3.1 En relación con los cinco principales componentes de la identidad colectiva que presentábamos, es posible hablar de una variable intensidad de integración o pertenencia a una determinada identidad cultural:

- en el plano personal, proporcional al grado de participación en los cinco componentes de la identidad. Por ejemplo, es claro que la pertenencia a una determinada identidad se debilita en la medida en que una persona ya no vive en el territorio étnico y no vive con el grupo que es el sujeto histórico de esa identidad.

- en el plano col ectivo en proporción al grado de vigencia e integración interna entre esos mismos cinco elementos que constituyen la identidad o el etnotipo.

3.2 Cuanto más integración en el plano colectivo, el etnotipo que normalmente funciona como filtro ante las entradas de nueva información o propuestas de cambios culturales, se mostrará con más intolerancia y conflictividad. Es la razón por la que los cambios religiosos en las comunidades campesinas o indígenas presentan niveles de mayor beligerancia y el cambio religioso se produce en forma más traumática. Una familia protestante en una ciudad pasa inadvertida, mientras que una pequeña comunidad representa la ruptura o interrupción de toda una red de relaciones sociales, ceremoniales e incluso laborales.

3.3 Es importante tener en cuenta que la normatividad jurídica que los Estados modernos han impuesto a todas las colectividades culturales que albergan, ha tenido como consecuencia importantes cambios en la actitud ante los innovadores culturales. Ya no es jurídicamente 
posible eliminar a un innovador que desasosiega la vida de una comunidad mientras se encuentre dentro del marco constitucional del EstadoNación.

Un cambio cultural con más alto grado de conflictividad no significa que la identidad se pierda o resulte amenazada sino que la dialéctica de su transformación aumenta y que su capacidad homeostática recibe un desafio mayor. Lo normal es que la homeostasis se imponga y el sistema cultural integre el cambio. Las actuales y futuras crisis locales que el cambio religioso planteará, en principio, deben ser situadas como parte de este proceso. Al final del mismo la identidad colectiva habrá sobrevivido incorporando nuevos perfiles de identidad, nuevos rasgos a un rostro siempre cambiante.

3.4 Un cambio de religión implica un desequilibrio coyuntural en la identidad cultural que se inscribe, en la terminología de Fernand Braudel, dentro de la larga duración. No tenemos muchos casos de comunidades en los que la conflictividad y beligerancia entre la religión tradicional y una nueva religión perdure por 30 o 50 años, que es el plazo de la coyuntura de Braudel. Las tensiones sí pueden durar y se convierten en parte de la estructura social y se harán presentes en diferentes momentos de la vida cotidiana (conformación de matrimonios, por ejemplo). Pero, pasada la coyuntura, todo indica que el sistema logró su equilibrio y la colectividad se reconoció a sí misma (identidad) a pesar de los cambios. Los plazos de esta coyuntura se acortan en el medio urbano que por su complejidad, despliega un mayor margen de tolerancia y asimilación del cambio y del pluralismo en los comportamientos. En este sentido, independientemente de la opinión que se tenga del continuo folk-urbano de Redfield, parecería que el destino del proceso de cambio religioso que se producen en las comunidades cerradas apunta hacia la tolerancia y el pluralismo de las comunidades complejas y abiertas. Así en zonas recientemente urbanizadas como Río Bravo (Tamaulipas), objeto de una investigación en curso por nuestra parte, encontramos una exuberante proliferación de cultos, templos y denominaciones y una rápida adecuación de la cultura local tradicional (católica) a una convivencia plural y diversificada religiosa- 
JOSÉ LUIS GONZÁLEZ

mente. Pero en este caso se deben tener en cuenta tres aspectos peculiares: a) que la misma comunidad en su conjunto tiene una corta historia, b) su cultura es cultura de aluvión y el catolicismo es, quizás, el único elemento común aunque proveniente de diversos lugares del interior; y c) la proximidad con la frontera y con otra cultura (EE.UU.).

3.5 A veces se ha centrado demasiado la atención en las manifestaciones conflictivas y momentáneamente desestabilizadoras de los cambios religiosos en comunidades indígenas o rurales cuando se trata de poner en discusión los procesos de cambios en la identidad cultural. Creo que es necesario prestar atención también al modo como esos mismos cambios se producen en la ciudad. El tipo de cohesión social que requiere y exige la vida urbana no excluye a quienes cambian de religión. $\mathrm{Su}$ pertenencia a la colectividad no es puesta en tela de juicio.

3.6 Sin duda son los componentes 'conciencia de pertenencia' y 'voluntad de vivir juntos' los aspectos que resultan más afectados por la reubicación religiosa que implica la experiencia del cambio religioso a nivel personal y colectivo. Es un proceso de reformulación de significados en cuyo interior va recibiendo nuevas interpretaciones y respuestas la tradición cultural e histórica del sujeto como efecto del carácter globalizante que, a modo de teoría general, conserva la religión. ${ }^{11}$ Es abundante la información de trabajos y de testimonios directos de comunidades y personas que pertenecen a denominaciones protestantes que representan la vertiente indiscutible de un nacionalismo mexicano no católico. Los mismos casos son ejemplo de una cultura que ha integrado el cambio religioso en un sector significativo de su población y evocan la posibilidad de una reconfiguración más profunda de la sociedad mexicana dentro de los mecanismos de una misma identidad que se reedita constantemente.

${ }^{11}$ C. Geertz, La interpretación de las culturas, 1991, México, Gedisa, p. 89. 
RELIGIONES E IDENTIDADES

\section{Sin conclusión final}

Cuando se trata de procesos culturales, no es posible hablar de conclusiones. La cultura continúa; los actores se reacomodan; nuevos factores entrarán en juego $\mathrm{y}$, mientras el tiempo no se detenga, las sorpresas estarán agazapadas en cada recodo del camino.

- Los procesos de cambio religioso que se están produciendo no son sólo hechos aislados sino parte de una tendencia de cambios cuyas causas hay que buscarlas más allá de las fronteras geográficas y culturales. Esta tendencia acompañará y nos atrevemos a creer que se profundizará en el tránsito de la sociedad mexicana al siglo XXI.

- La relación entre cambio religioso e identidad cultural debe ser resituada en un plano antropológico y específicamente en el campo de la cultura y de los cambios culturales. Mucha de la beligerancia que en torno a este problema se ha desplegado proviene de la interferencia política que el problema ha sufrido. El análisis político pertinente para otros tópicos ha oscurecido esta discusión. Desde el plano cultural, todo indica que la cultura mexicana tanto en su nivel local como nacional seguirá perfilándose con una identidad cada vez más plural desde lo religioso. Este hecho y su consecuente efecto sobre el peso social del catolicismo como religión mayoritaria, podría tener efectos sobre la evolución de la institución católica y sobre sus relaciones tanto con el Estado como con la sociedad mexicanos.

- Las identidades colectivas rurales y étnicas serán las que todavía continuarán enfrentando el desafío del pluralismo religioso con un mayor grado de conflictividad. Un sistema que funciona sobre la base de una gran cohesión social dificilmente soporta la innovación, sobre todo en aspectos tan medulares como la tradición religiosa y ceremonial íntimamente entrelazadas al conjunto del sistema cultural. En este nivel hay un interrogante pendiente: el resurgimiento de lo étnico y la crisis del esquema Estado-Nación como respuesta a las identidades étnicas que engloba, deja una brecha de incertidumbre y, casi, de amenaza (como se ha puesto de manifiesto dramáticamente en Europa del Este). 
JOSÉ LUIS GONZÁLEZ

De no resolverse adecuadamente las relaciones estructurales entre el Estado y los grupos étnicos, el repliegue cultural podría ser una estrategia inevitable y, en ese caso, la religión tradicional un baluarte.

En ese caso, frente al pluralismo y tolerancia del Estado moderno, la identidad étnica podría oponer una tradición religiosa endurecida e intransigente.

- Por lo demás todo indica que una identidad nacional como la mexicana (con el peculiar grado de integración que es posible lograr en un plano tan amplio) podría soportar perfectamente un perfil de identidad no católica sin que se viera en peligro de desintegración ni de crisis traumáticas. El que esto ocurra y el modo como ocurra depende no sólo de la cultura sino de la sociedad y del comportamiento de sus instituciones, así como de su interacción con procesos culturales y sociales supranacionales. De hecho, son muchos los indicios de que, en cierto modo, el futuro ya nos ha alcanzado y puede ser soportable. 